\title{
FAÇO SENTIDO; LOGO, APRENDO: AS PROPRIEDADES DO SENSEMAKING NA APRENDIZAGEM EXPERIENCIAL
}

\section{RESUMO}

Adrianne Garcia ${ }^{1}$

Ludmilla Meyer Montenegro²

0 presente estudo teve como objetivo de entender como a reflexividade e a aprendizagem experiencial se relacionam ao processo de sensemaking em suas sete propriedades, elencadas por Weick (1995). Por meio de um ensaio teórico, foram abordadas as teorias da aprendizagem experiencial, reflexividade e sensemaking, propondo a articulação entre essas teorias, sobretudo no que diz respeito às sete propriedades do sensemaking no modelo de aprendizagem experiencial apresentado por Kolb (1976). Conclui-se que o processo de sensemaking e o Ciclo de Aprendizagem Experiencial são semelhantes e complementares, e, dessa forma, foi possível encontrar as propriedades do sensemaking também no Ciclo de Aprendizagem.

Palavras-Chave: Sensemaking; Aprendizagem Experiencial; Reflexividade.

TENGO SENTIDO, POR LO TANTO, APRENDO: LAS PROPIEDADES DE LA CREACIÓN DE SENTIDOS EN EL APRENDIZAJE EXPERIENCIAL

\section{RESUMEN}

Este estudio tuvo como objetivo comprender la reflexividad y el aprendizaje experimental relacionado con el proceso de creación de sentido en sus siete propiedades, enumeradas por Weick (1995). A través de un ensayo teórico, se abordaron como las teorías del aprendizaje experimental, la reflexividad y la creación de sentido, proponiendo una articulación entre teorías, especialmente en el sentido de siete propiedades de creación de sentido, en el modelo de

\footnotetext{
1 Mestre em Administração pelo Programa de Pós-graduação em Administração da Universidade Federal de Sergipe
}

2 Professora do Programa de Pós-graduação em Administração da Universidade Federal de Sergipe 
aprendizaje experimental presentado por Kolb (1976). Se concluye que el proceso de creación de sentido y el Ciclo de aprendizaje experiencial son similares y complementarios, por lo que fue posible encontrar propiedades de creación de sentido también en el Ciclo de aprendizaje.

Palabras clave: Sensemaking. Aprendizaje Experiencial. Reflexividad.

\title{
I MAKE SENSE THEREFORE I LEARN: THE PROPERTIES OF SENSEMAKING IN EXPERIENTIAL LEARNING
}

\begin{abstract}
This study aimed to understand reflexivity and experiential learning related to the sensemaking process in its seven properties, listed by Weick (1995). Through a theoretical essay, they were approached as the theories of experiential learning, reflexivity and sensemaking, proposing an articulation between theories, especially in the sense of seven sensemaking properties, in the experiential learning model presented by Kolb (1976). It is concluded that the sensemaking process and the Experiential Learning Cycle are similar and complementary, and, therefore, it was possible to find as sensemaking properties also in the Learning Cycle.
\end{abstract}

Keywords: Sensemaking. Experiential Learning. Reflexivity.

\section{INTRODUÇÃO:}

Os estudos sobre sensemaking ainda têm atraído muitos pesquisadores, sobretudo nas pesquisas de paradigma interpretativista na área de estudos organizacionais. 0 sensemaking tem sido investigado no sentido de analisar como as pessoas compreendem e criam as suas realidades (BROWN; COLVILLE; PYE, 2015). Não existe ainda uma definição absoluta de sensemaking, mas há um consenso sobre os processos que buscam entender de forma plausível as questões e eventos ambíguos. 
À medida que o indivíduo se relaciona com os mais distintos grupos, existe uma troca intersubjetiva de informação, estabelecendo uma comunicação por meio de símbolos. Essa interação do indivíduo com outros sujeitos e as experiências com situações cotidianas no ambiente organizacional o auxilia na sua formação de visão de mundo, na sua construção de sentido sobre as coisas que o cercam. As respostas dadas pelo indivíduo não fazem parte apenas de uma reação a um estímulo, mas ela passa por um filtro de interpretação, observação, reflexão e atinge sua forma final (HILDEN; TIKKAMÄKI, 2013; JORDI, 2011; SPINILLO; ROAZZI, 1989; KOLB, 1976).

O indivíduo que passa a experimentar situações dentro da organização tende a aprender com essas experiências (DEWEY, 1952; KOLB, 1976). Essa aprendizagem experiencial está atrelada ao ato de refletir. $\mathrm{O}$ ato de refletir e aprender guarda semelhanças com o sensemaking e suas sete propriedades elencadas por Weick (1995).

No tocante à Teoria da Aprendizagem Experiencial, Kolb (1984) sugere que as teorias racionalistas e outras teorias cognitivistas tendem a dar importância primordial à aquisição, manipulação e uso de símbolos abstratos, enquanto teorias comportamentais negam qualquer papel da consciência à experiência subjetiva no processo de aprendizado. Segundo o autor, isso tem levado à construção de uma imagem incompleta de como se dá a aprendizagem, de forma que a Teoria da Aprendizagem Experiencial busca sugerir uma perspectiva holística e integrativa, combinando experiência, percepção, cognição e comportamento.

Com a intenção de contribuir com a construção dessa imagem no tocante à reflexividade e aprendizagem, o presente estudo tem como objetivo de entender como a reflexividade e a aprendizagem experiencial se relacionam ao processo de sensemaking em suas sete propriedades elencadas por Weick (1995).

Este ensaio está dividido em 5 seções. Inicialmente busca-se apresentar o contexto da aprendizagem experiencial e reflexividade e o sensemaking, trazendo suas semelhanças, e apresentando o objetivo dessa pesquisa. Na sequência, são apresentados os conceitos de 
sensemaking e suas propriedades, trabalhando, também, nas críticas levantadas por estudiosos nos últimos anos. Em seguida, apresentam-se os conceitos de aprendizagem e reflexividade, destacando-se o Ciclo de Aprendizagem Experiencial de Kolb (1976). Na sequência, apresentam-se as propriedades do sensemaking na aprendizagem experiencial, atendendo ao objetivo da presente pesquisa em entender como a reflexividade e a aprendizagem experiencial se relacionam ao processo de sensemaking em suas sete propriedades. 0 artigo finaliza com as considerações finais, trazendo as contribuições do estudo, suas limitações e sugestões para pesquisas futuras.

\section{O SENSEMAKING E SUAS PROPRIEDADES}

Maitlis e Christianson (2014) entendem que o sensemaking - criação de sentido - é um dos processos essenciais nas organizações, à medida que as pessoas desempenham um papel na construção das situações que tentam entender. 0 termo sensemaking corresponde ao seu significado literal: fazer sentido. Os estudiosos o definem das mais variadas formas, gerando uma série de conceitos na literatura. Louis (1980) argumenta que, no cotidiano organizacional, o indivíduo lida com eventos corriqueiros, em que não há o elemento surpresa. De forma inconsciente, esse indivíduo lida com essas situações seguindo um roteiro já estabelecido em sua cognição. Porém, ao lidar com o elemento surpresa, este mesmo indivíduo necessita trazer a consciência os relatos ocorridos, fazendo uma retrospecção, a fim de compreender o que não está dentro da rotina. Portanto, para a autora, o sensemaking lida com a retrospecção como meio de explicar fenômenos surpresa ocorridos.

O conceito de Starbuck e Milliken (1988) sobre sensemaking baseia-se na ideia do framework - quadro de referência - em que o indivíduo coloca estímulos (percepções, crenças sobre o que é, crenças sobre o que deveria ser, reflexão de hábitos), a fim de que seja direcionado por meio dele. Quando esse indivíduo coloca estímulos nesse framework é possível gerar uma compreensão, um entendimento, uma explicação, uma atribuição, uma 
extrapolação e uma predição. Esse processo tende a gerar um sentido e esclarecer a visão do indivíduo quanto a direção a ser seguida.

Gioia e Chittipeddi (1991) entendem sensemaking como uma reconstrução contínua de sentidos que ocorre no quadro de referência de determinado processo, a fim de compreendê-lo. Maitlis e Christianson (2014, p. 67) definem sensemaking como:

Um processo induzido por expectativas violadas, que envolve atender e dar suporte a dicas extraídas do ambiente, criando um significado intersubjetivo por meio de ciclos de interpretação e ação, e assim criando um ambiente mais ordenado para que dicas posteriores possam ser pautadas (tradução nossa).

Para os fins dessa pesquisa, o conceito adotado é o de Weick (1995), que trata o sensemaking como a criação de sentido que envolve a acomodação de estímulos em quadros de referências, compreendendo esses estímulos, reparando elementos surpresa, para que haja uma compreensão mútua a padronizada desse sentido. 0 autor esclarece que o sensemaking não trata tão somente de um processo de interpretação, embora a interpretação seja parte essencial do processo (MONTENEGRO, 2009).

Machado-da-Silva, Fonseca e Crubellate (2005, p.26) argumentam que "a interpretação é o mecanismo operacional, de natureza cognitivo-cultural, da recursividade inerente à institucionalização". Para Daft e Weick (1984, p.286) é “o processo de traduzir os eventos e desenvolver o entendimento compartilhado e esquemas conceituais entre os membros da alta gerência". Enquanto o sensemaking busca entender o processo de "como" ocorre a construção do sentido, a interpretação descreve a forma de entender determinada ação, contexto ou objeto.

Maclean, Harvey e Chia (2012) sugerem três processos do sensemaking: (1) localizar localizar a história no tempo e o papel do sensemaker na história; (2) fazer sentido expressão da opinião, crença ou lição; (3) Vir a ser - tomando como base o passado e o presente, projeta-se o futuro. 
Segundo Maitlis e Christianson (2014), existe um rápido crescimento na literatura sobre sensemaking em que se examina como ocorre esse processo nas organizações. Desde a publicação da pesquisa de Weick, as pesquisas envolvendo sensemaking cresceram e tornaram-se metodologicamente rigorosas. A literatura sobre sensemaking foi sendo fragmentada, divergindo em alguns pontos. Para alguns, o sensemaking trata-se de um processo individual cognitivo (LOUIS, 1980; STARBUCK; MILLIKEN, 1988), para outros tratase de um processo social e discursivo (WEICK, 1995; MAITLIS, 2005). A questão da retrospecção e prospecção também fica em evidência nesses estudos em que os autores divergem quanto a essa propriedade (MAITLIS; CHRISTIANSON, 2014).

Ao longo do tempo, a literatura sobre sensemaking, influenciada pela perspectiva Weickana, percorreu aspectos socioconstrutivistas em detrimento das suas fortes origens cognitivistas. Esse aspecto foi refletido, sobretudo, em pesquisas que tinha como foco a linguagem, ao invés da cognição (COLVILLE; PYE; BROWN, 2016; MAITLIS; CHRISTIANSON, 2014; KUZNETSOV; KUZNETSOVA, 2014; ROULEAU; BAGOLUN, 2011; ROBICHAUD; GIROUX; TAYLOR, 2004). Nesse sentido, o sensemaking tem significado "fazer algo" sensato, de maneira não somente cognitiva, mas como uma prática social construtivista. Enquanto na versão cognitivista, o sensemaking leva à formação de mapas de causas mentais compartilhadas, na versão construtivista, leva à intersubjetividade construída através da linguagem (SANDBERG; TSOUKAS, 2015).

Cornelissen e Schildt (2015) fazem uma análise sobre as várias formas pelas quais o sensemaking tem sido utilizado na pesquisa, sobretudo em relação à estratégia como prática. Segundo os autores, essa teoria tem se conectado com outras construções teóricas e tradicionalmente socioconstrucionistas e sociocognitivas. 0 foco central do sensemaking e da estratégia como prática, no entanto, tem sido sobre a formação do alinhamento dentro e entre os diferentes níveis hierárquicos organizacionais. Segundo os autores, o que mais chama a atenção nesses estudos é a forma como o sensemaking é utilizado: não como uma teoria ou perspectiva, mas como um fenômeno empírico. 
Vale ressaltar que, embora a ideia tradicional de estratégica gire em torno nos níveis hierárquicos mais elevados dentro da organização, a estratégia como prática social, derivada das Teorias da Prática, sustenta a ideia de que a estratégia é algo a ser construído pelos seus praticantes, seja individualmente ou em grupo, que manipulam símbolos, linguagens e outras ordens estabelecidas (JALONEN; SCHILDT; VAARA, 2018; VAARA; WHITTINGTON, 2012; JARZABKOWSKI; SPEE, 2009). Essa perspectiva enfatiza aspectos processuais e sociais dos principais elementos estratégicos em detrimento do seu resultado, reconhecendo a estratégia em múltiplos níveis organizacionais potencialmente relevantes (ASMUß, 2018). Na perspectiva da prática social, os conceitos estratégicos derivados da linguagem e de símbolos contribuem para a visão no nível micro da estratégia, tendo em vista a interação e construção de sentido por parte dos indivíduos praticantes (JALONEN; SCHILDT; VAARA, 2018).

Esses praticantes não se limitam à alta gerência da organização, mas a todos os atores que contribuem para a formação, elaboração e execução da estratégia. Assim, esses indivíduos podem estar dentro da organização ou não, mas influenciam de alguma forma o "fazer" estratégia (strategizing) (WHITTINGTON, 2006).

Quanto aos estudos na área organizacional, Maitlis e Christianson (2014) apontam que vêm sendo explorados os seguintes temas: aspectos ambientais, crises organizacionais, ameaças à identidade da organização, mudança organizacional.

Diante dos conceitos sobre sensemaking que circulam na literatura, foi possível elencar sete propriedades visíveis nesse processo (WEICK, 1995). Essas características fazem uma distinção mais clara entre o processo de sensemaking dos demais processos (entendimento, interpretação, atribuição).

A primeira propriedade é que o sensemaking é fundamentado na construção de identidade. Para que o processo seja iniciado é necessária a figura do sensemaker, ou seja, o indivíduo que vai dar sentido a algo. Esse indivíduo possui uma identidade que é formada a partir de uma série de interações entre diversos atores, inclusive sendo manifestado o seu "eu" de acordo com a situação que lhe ocorre. A depender da situação em que este indivíduo 
esteja inserido, ele irá avaliar qual "eu" é mais apropriado para ser manifestado (WEICK, 1995; GOFFMAN, 1999).

A construção da identidade envolve um processo de natureza cognitiva em que o conjunto de ideias, crenças e valores adquiridos interferem nas ações do indivíduo, inclusive limitando a sua racionalidade diante da tomada de decisão (LOBLER; SIMONETTO, 2010; MACHADO-DA-SILVA; FONSECA; FERNANDES, 1999; PEREIRA). Segundo Correia-Lima, Rigo e Santos (2016), a construção de identidade envolve elementos do passado e do presente, sendo um processo contínuo, dinâmico, fluido.

Esse mesmo processo de construção ocorre no meio organizacional. Estudos recentes sugerem que o processo de identidade é resultado de uma produção discursiva e simbólica (MONTEIRO et al., 2017), sendo, portanto, um processo dinâmico e subjetivo, desprezando a ideia exclusiva de objetividade e racionalidade. As interações decorridas no ambiente organizacional geram no indivíduo a construção de uma identidade coletiva própria daquele meio em que está inserido.

Monteiro et al. (2017, p. 80) sugerem que a "construção de identidade dos sujeitos ocorre a partir de uma identificação com o outro, seja por intermédio de grupos aos quais pertence ou da sociedade em geral". Assim, é possível identificar a complexidade nesse processo de construção, que envolve também situações conflituosas. Segundo os autores, os indivíduos assumem papeis sociais por conta da realidade social vivida, construindo conceitos de identidades que surgem no decorrer das histórias sociais.

Essa identidade organizacional faz com que o indivíduo aja como organização, evidenciando crenças, valores e objetivos adquiridos dessa coletividade (CHATMAN; BELL; STAW, 1986). Existe uma diferença entre a identidade da organização e identidade na organização. 0 primeiro termo diz respeito a uma correlação entre elementos da identidade individual, organizacional e coletiva. Já o segundo diz respeito a uma análise que parte do nível individual ao organizacional, estabelecendo três critérios dessa análise: distintividade, continuidade temporal e centralidade (PIMENTEL; CARRIERI, 2011). Ainda, segundo Weick 
(1995), as situações são interpretadas ou passam a significar algo a partir de quem o indivíduo é. Dessa forma, ele constrói o seu sentido sobre determinada ação baseado na construção da sua própria identidade, de como ele se enxerga.

Vale ressaltar que a questão da identidade nas organizações tem sido bastante explorada pela literatura, relacionando-a com outros temas tais como: territorialidade e identidade (SANTOS; DAVEL, 2018; TEIXEIRA; SARAIVA; CARRIERI, 2015; SARAIVA; CARRIERI; SOARES, 2014), questões de gênero (MOTA;SANTOS; CARVALHO NETO; OLIVEIRA; ANDRADE, 2019; MOURA; NASCIMENTO; BARROS, 2017; ETTINGER et al., 2015; CANABARRO; SALVAGNI, 2015), teoria queer (RUMENS; SOUZA; BREWIS, 2019; SOUZA, 2017; PULLEN et al., 2016), a dinâmica das organizações públicas (GOMES et al., 2016). É possível sugerir que esse fenômeno tem ocorrido devido às mudanças sociais significativas que vêm ocorrendo nas últimas décadas.

Para Mills, Thurlow e Mills (2010), a construção da identidade é indiscutivelmente componente chave no processo, tanto por influenciar o sensemaking individual, mas também porque influencia os indivíduos a entenderem as outras seis propriedades em questão. De acordo com Weick (1995), o sensemaking entre em colapso quando a identidade não é clara, uma vez que o contexto social e as pistas extraídas tornam-se ambíguas, a retrospectiva se torna mais difícil e os eventos contínuos tonam-se mais resistentes às limitações e a plausibilidade torna-se mais distorcida.

A segunda característica encontrada no sensemaking é que ele é retrospectivo. Essa característica que permeia o processo talvez seja o maior elemento singular que o distingue de outros processos (WEICK, 1995). Por meio da retrospecção, o indivíduo passa a refletir sobre a experiência vivenciada, trabalhando na reconstrução da sequência de atos. Por tratarse de uma memória, não é possível reproduzir com fidelidade a ocorrência dos fatos. Por outro lado, considera-se, ainda, que esse processo possui uma elevada importância, tendo em vista ser a principal maneira de resgatar a história (MONTENEGRO, 2009). 
Giddens (2009) defende que a memória é um dispositivo de lembrança, de forma que recupera informações ou relembra informações. Sob essa perspectiva, o autor defende que o passado está separado do presente, e que a memória traz o passado ao presente. No contexto organizacional essa característica também é discutida e apresenta-se como de grande relevância para a literatura: a memória organizacional tem a capacidade de responder perguntas sobre o ambiente por meio da retrospecção dos seus indivíduos, que retém e recupera informações para o presente por meio dos sistemas sociais (STEIN, 1995).

Além disso, Weick (1995) aponta três aspectos que são necessários relembrar sobre o processo de entender um evento depois que ele ocorre: (1) as pessoas estão conscientes de alguns eventos basicamente apenas no momento em que eles ocorrem; (2) a retrospecção apenas deixa o passado mais claro que o presente ou futuro, mas não tem o poder de deixá-lo transparente (STARBUCK; MILLIKEN, 1988); (3) o sentimento de clareza, ordem e racionalidade são objetivos importantes no processo de sensemaking, de forma que, quando alcançados, o processo de retrospecção finaliza.

Einola et al. (2017) afirmam que essa propriedade do sensemaking ainda é pouco explorada pela literatura, no que diz respeito ao estudo do sensemaking retrospectivo, tendo em vista que os autores têm se limitado à visão prospectiva do sensemaking e do uso de mapas cognitivos para melhorar a compreensão compartilhada. Dessa forma, os autores contribuíram para a literatura ao conceituar o sensemaking relacional, fornecendo conhecimentos sobre seus mecanismos e sintetizando uma estrutura explicita para facilitar o sensemaking relacional em sua área de estudo (offshores de P\&D).

Sandberg e Tsoukas (2016) discordam dessa visão, sugerindo que investigadores de áreas como estratégia e mudança organizacional (que se concentram especialmente no futuro) criticam essa perspectiva justamente pela ênfase na retrospecção e não na prospecção. De fato, o aspecto socioconstrutivista da perspectiva Weickana contempla com maior ênfase os aspectos retrospectivos, e não prospectivos, que são mais aplicados à visão cognitivista de sensemaking. 
A terceira propriedade do sensemaking é que ele é criado em ambientes sensatos. Segundo Weick (1995), as duas primeiras propriedades são bastante envolvidas com o "sentido", enquanto esta característica está mais ligada ao "fazer". 0 indivíduo, segundo o paradigma interpretativista, cria a sua realidade a partir da forma como enxerga o mundo ao seu redor (BURRELL; MORGAN, 1979).

Ao mesmo tempo em que o indivíduo cria a sua realidade, existem outras realidades dentro da sua própria - outras pessoas, outros objetos, outros eventos - e estes existem independente da sua vontade. A realidade assumida por um indivíduo é um recorte de uma realidade maior. Essa realidade ganha significados a partir de linguagens e objetos e é dinâmica, podendo ser modificada a partir do mercado de ideias (BERGER; LUCKMANN, 2004). Weick (1995) utiliza a palavra enactment (criação) a fim de preservar o processo que ocorre na organização: o indivíduo produz parte do ambiente organizacional em que está inserido. De acordo com Munck (2015, p. 529), são os "discursos performáticos que os atores promulgam e reconhecem".

A quarta propriedade diz respeito a ser um processo social. 0 processo de sensemaking, por envolver a atribuição de sentido a algo, está necessariamente relacionado ao aspecto social. É por meio das interações entre os atores que se gera internamente um conceito sobre algo. A cognição do indivíduo, como já citada anteriormente, é produto de uma série de interações sociais e sentidos compartilhados (POSSAS; MEDEIROS, 2016; BAUER; MESQUITA, 2007). Segundo Weick (1995), o processo de sensemaking não é solitário, pois o que uma pessoa faz, ainda que internamente, envolve atores externos.

Essa característica social do sensemaking é embasada principalmente por meio de conversas, discursos e conversações. Os estudiosos no processo então atentos a esses eventos, pois a interação social ocorre justamente por meio deles (WEICK,1995). Dentre todas as características citadas, o "ser social" é, possivelmente, a característica que mais relaciona com as demais. É possível encontrá-la no processo de construção da identidade, bem como na promulgação de discursos e na dinamicidade do processo de sensemaking. 
0 quinto elemento diz respeito à dinamicidade do processo. 0 sensemaking possui essa característica por não ter um ponto de início. Diante das propriedades anteriores, é possível perceber que o sensemaker está num constante processo de mudanças. Dessa forma, a sua criação de sentido pode ser modificada constantemente durante esse percurso (WEICK, 1995). Segundo Montenegro (2009), devido ao caráter contínuo do sensemaking, é necessário fazer um recorte metodológico, a fim de analisá-lo em uma situação específica.

O foco em e por dicas (sinais) extraídas é a sexta propriedade desse processo. Nesse quesito, entende-se que essas dicas seriam uma "pré-amostra" do que estaria por vir. A partir dessas dicas, que Weick (1995) compara com "sementes", seria possível ter uma ideia mais ampla sobre o que poderia estar acontecendo em determinada situação.

Dentro desse contexto, Starbuck e Milliken (1988) consideram que essas dicas são extraídas por meio do processo de noticing, que se refere a atividades de filtragem, classificação e comparação, enquanto o sensemaking está mais envolvido com a interpretação e a atividade de determinar o significado das dicas extraídas. Daft e Weick (1984) sugerem a ideia de scanning, que soa mais estratégica, mais consciente, mais intencional, mais controlada por preconcepções e menos aberta à intervenção que o noticing (WEICK,1995). Para Daft e Weick (1984), no scanning os dados podem variar de acordo com a fonte e a aquisição, dependendo do modo de interpretação da organização.

Por fim, o sensemaking tem como última propriedade ser dirigido por plausibilidade em vez de acurácia/precisão. Apesar do esforço da maioria dos gerentes em organizações ser voltado para diminuir a incerteza e aumentar a precisão diante das suas percepções, nem sempre é possível obter sucesso nesse quesito. A questão da acurácia no processo de sensemaking não é necessária, uma vez que ele é guiado pela plausibilidade, pragmatismo, coerência, razoabilidade, criação, invenção e instrumentalidade (WEICK, 1995), e envolve a percepção interpessoal, que é intersubjetiva. A precisão, nesse caso, é um quesito dispensável, uma vez que o processo de sensemaking é dinâmico e retrospectivo, em que é possível encontrar estórias diferentes, mas não completamente fieis à realidade ocorrida. Plausíveis, mas não completamente ideais. 
Mills, Thurlow e Mills (2010) sugerem que a plausibilidade e a construção de identidade são a chave para entender como algumas vozes são ouvidas em detrimento de outras e por meio do sensemaking crítico, que pode ser gerado por meio de alguns fenômenos, tais como a cultura de gênero ou organizacional e práticas organizacionais discriminatórias.

Algumas críticas foram feitas à perspectiva do sensemaking nos últimos anos, contradições e ambiguidades que sugerem áreas de potencial desenvolvimento para pesquisas futuras. Sandberg e Tsoukas (2015) afirmam que a menos que os principais conceitos e suposições da perspectiva do sensemaking sejam revisados e criticados constantemente, é improvável que ela avance criativamente.

Os autores se concentram em cinco aspectos críticos que consideram mais relevantes sobre a perspectiva em questão. A primeira delas diz respeito à ênfase na retrospecção em lugar da prospecção. Na visão Weickana, a visão direcionada para o futuro é essencialmente derivada de um sensemaking retrospectivo - chega-se à visão de futuro por meio de uma retrospecção do que já aconteceu. Os autores reforçam que estudiosos, sobretudo de áreas como estratégia e mudança organizacional (disciplinas orientadas para o futuro da organização) fazem queixas à ênfase na retrospecção, tornando carentes os estudos prospectivos. No entanto, quando o sentido de sensemaking prospectivo é visto como derivado da retrospecção, alguns autores divergem de Weick sobre a maneira como ele ocorre.

Para Weick (1969 apud SANDBERG; TSOUKAS, 2015), o significado das ações planejadas necessárias para realizar uma atividade só podem ser descobertas porque são vistas como algo que já aconteceu, ou seja, são fruto de uma construção de sentido retrospectivo. Nesse caso, a noção de fazer sentido no "futuro perfeito" ocorre por meio da retrospecção no "passado imperfeito". McKay (2009 apud SANDBERG; TSOUKAS, 2015) entende que pensar no "futuro perfeito" seria inadequado para entender possíveis processos de sensemaking, cujas situações predominam a incerteza e a complexidade. 
A segunda crítica envolve a noção de "processo", que permanece vaga. Alguns pesquisadores (JEONG; BROWER, 2008; MILLS; WEATHERBEE, 2006; DECKER; 1998; O'CONNELL, 1998; MAGALA, 1997; GIOIA; MEHRA, 1996) argumentaram que o real processo de construção de sentido permanece relativamente vago, não sendo suficientemente explorado e dando origem a confusões em seu sentido. Alguns conceitos em sensemaking como criação e interpretação são corriqueiramente confundidos, apesar das veementes afirmações sobre a divergência entre sensemaking e esses conceitos (SANDBERG, TSOUKAS, 2016, WEICK, 1995). Outro aspecto bastante confuso é a propriedade da promulgação (enactment) - ela estaria ligada a um único ou a múltiplos processos?

Partindo ao terceiro ponto, estudiosos apontam que a noção de "sentido" é insuficientemente desenvolvida, permanecendo vago e impreciso (SANDBERG; TSOUKAS, 2015; O'CONNELL, 1998; GIOIA; MEHRA, 1996). Sandberg e Tsoukas (2015) sugerem que a noção de "sentido" aparece com múltiplos significados na literatura, inclusive do próprio Weick, sendo alguns deles: compreensão intelectual de uma situação disruptiva, percepção, significado, compreensão e reflexão.

O quarto ponto de crítica gira em torno de que contextos maiores em que ocorre o sensemaking são negligenciados. Segundo Sandberg e Tsoukas (2015), embora essa seja uma crítica menos frequente, alguns autores apontam a negligência dos estudos em sensemaking em contextos institucionais maiores (WEBER; GLYNN, 2006; MAGALA, 1997; TAYLOR; VAN EVERY, 2000). Magala (1997) aponta a existência de uma desconsideração com os macroatores na perspectiva Weickana, sobretudo no tocante às restrições institucionais que apenas assumem a aparência micro-interacional. Essa crítica é, inclusive, reconhecida por Weick, Sutcliffe e Obstfeld (2005).

Por fim, estudiosos fazem críticas à realidade do ponto de vista do sensemaking, que parece ser reduzida à subjetividade, à medida que sugere que os atores "encenam" seu ambiente de acordo com seus próprios desejos (SANDBERG; TSOUKAS, 2015). Os autores que defendem essa crítica embasam seu posicionamento no fato de que o ambiente não é construído à vontade dos atores, pois existem propriedades que não podem ser 
representadas e modificadas à livre vontade de atores organizacionais, como é o caso das instituições sociais do capitalismo (CHILD, 1997; WHITTINGTON, 1988). Para Sandberg e Tsoukas (2015) essa crítica é infundada, tendo em vista que afirmar que o ambiente é promulgado não significa construí-lo e modifica-lo de livre vontade, mas diz respeito ao meio ambiente ser trazido à consciência dos atores, que fazem sentido do que percebem. 0 ambiente, nesse caso, é revelado e disponibilizado à experiência por meio de atividades intencionais de consciência (SANDBERG; TSOUKAS, 2015; THOMPSON, 2007).

\section{APRENDIZAGEM E REFLEXIVIDADE}

Arruda e Rossoni (2015) entendem que o indivíduo, ao longo do tempo, constrói uma bagagem de crenças e valores que dão sentido e trazem orientação na construção da estrutura organizacional. As situações organizacionais cotidianas com as quais os indivíduos lidam diariamente são geralmente novas e não esperadas. Diferente do que se acreditava diante da perspectiva racional de mundo - impregnada desde o surgimento do mundo dos negócios - não há como o indivíduo estar preparado para responder racionalmente alcançando sempre os melhores resultados (SOARES NETO, 2010), porém, essas situações cotidianas podem gerar experiências valiosas para o aprendizado organizacional.

No século XX, impulsionados pelo questionamento dos pressupostos positivistas da racionalidade, começam a surgir estudos referentes à aprendizagem experiencial e à prática reflexiva a partir dos trabalhos de John Dewey. No que diz respeito à aprendizagem experiencial, Dewey (1976) enfatiza a necessidade da experiência real do indivíduo com o objeto de sua relação, a fim de refletir por meio dessa experiência. Segundo Reis (2007), uma característica importante desse método empírico é que proporciona ao indivíduo ampliar suas investigações sobre determinado problema, ao passo que propicia reflexão sobre a experiência vivenciada. 
Essa experiência, segundo Dewey (1934) ocorre de forma contínua, pois a interação entre o indivíduo - ou criatura viva - e as condições ambientais estão envolvidas nesse processo de vida. Assim, a experiência é um processo inerente à vida do ser humano e que desencadeia em respostas que são encontradas a partir dessa experiência de interação com determinado objeto. Dewey (1952) sugere que quando a experiência é reflexiva, ou seja, quando se percebe o processo do antes e do depois de determinada situação, a incorporação conhecimentos novos ou mais densos será consequência natural.

Segundo Dewey (1959), o pensamento reflexivo é o exame ativo, prolongado e cuidadoso daquilo que se acredita ou do conhecimento hipotético, tendo como base os argumentos que o sustenta e as conclusões que se chega. Para o autor, a reflexão é um processo individual, sendo um fator cognitivo. Esse viés teórico cognitivo individual da reflexão também é defendido por diversos outros autores como Van-Bolhuis-Pootvliet, Daudelin, Boud, Keought, Walker, Boyd, Fales, Brown, McCartney, Schön, Seibert (REIS, 2007), porém outros estudiosos a veem com um enfoque social crítico (MERIZOW, 2000) ou cognitivo de reflexão pública (RAELIN, 2001).

Dentro dessa concepção de aprendizagem gerencial e prática experiencial, os trabalhos de Kolb (1976, 1984) e Schön (2000) mostram-se relevantes, tendo a vista sua orientação para a aprendizagem desenvolvida por meio da experiência.

O modelo de aprendizagem apresentado por Kolb (1984), com base nos estudos de Kurt Lewin, envolve quatro estágios que almeja explicitar como ocorre a aprendizagem experiencial, conforme Figura 4.

Figura 4. 0 modelo de aprendizagem experiencial de Kolb (1976) 


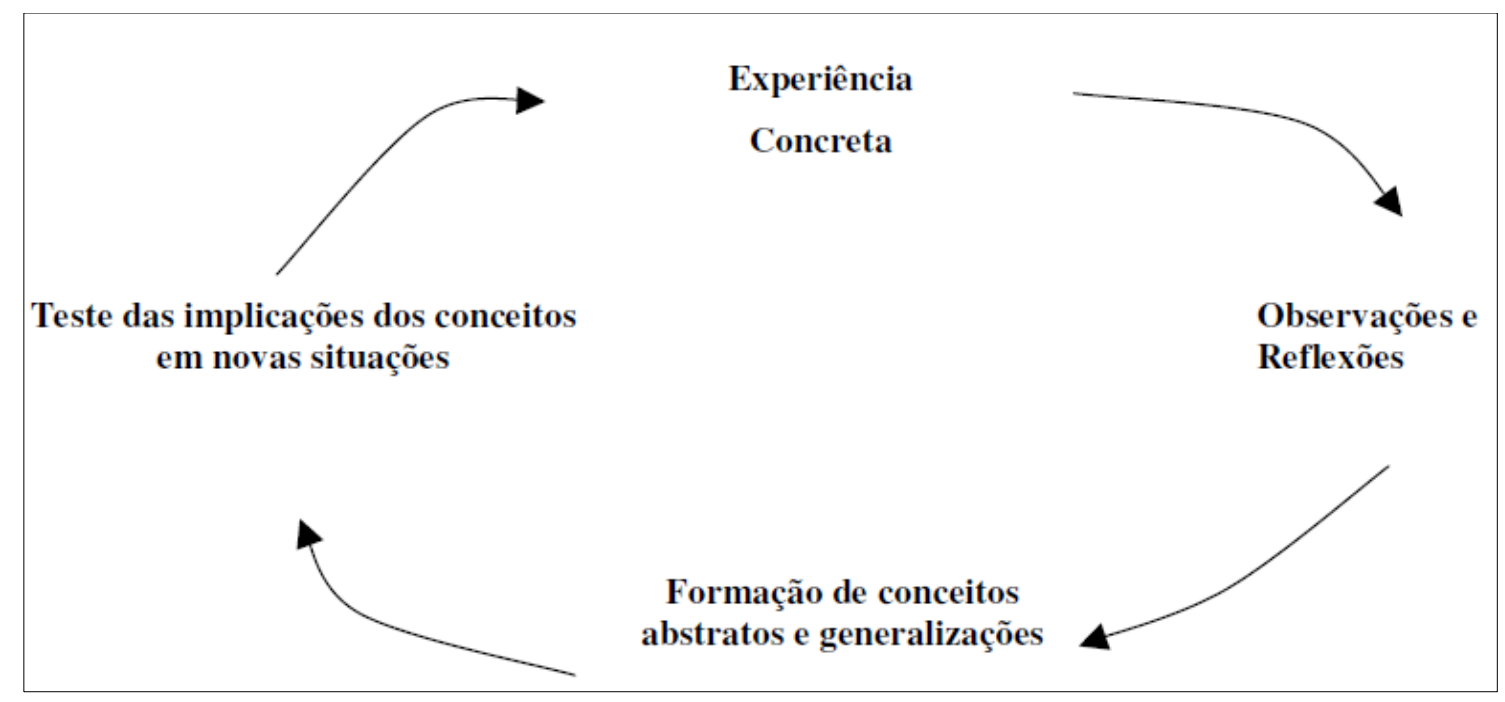

Fonte: extraído de Reis (2007) com base em Kolb (1976, p.22).

Segundo Kolb (1976) a aprendizagem é concebida em quatro estágios. 0 autor sugere que a experiência concreta imediata seja a base para observações e reflexões. A partir desse estágio, por meio das observações assimiladas são geradas novas possíveis implicações para determinada ação. Por fim, essas possíveis hipóteses de ação servem como direcionamento na criação de novas situações e experiências.

Kolb (1976) ainda afirma ser necessário um conjunto de quatro habilidades para ser efetivo enquanto aprendiz:

- Experiência concreta: estar apto a envolver-se completamente, e sem vieses, em novas experiências;

- Observação reflexiva: ser capaz de refletir e observar essas experiências por várias perspectivas;

- Conceitualização abstrata: ser capaz de criar conceitos que integrem suas observações de forma teoricamente lógica;

- Experimentação ativa: estar apto a usar essas teorias para tomar decisões e resolver problemas.

O modelo de Kolb (1984) foi testado empiricamente e considera que o conhecimento é gerado quando há a experiência, por meio da reflexão. A teoria da aprendizagem experiencial 
coloca a experiência como centro do aprendizado (KRAKAUER; SANTOS; ALMEIDA, 2017). No ciclo quadrifásico de Kolb, Pimentel (2007) chama atenção para a dialética existente entre o concreto e o abstrato, o reflexivo e o ativo. Kolb (1984) elenca algumas premissas norteadoras para a teoria da aprendizagem experiencial.

A primeira delas diz respeito à maneira como a aprendizagem é vista: não como um produto, mas como um processo. Esta premissa tem direta relação com a segunda, que sugere que aprendizagem experiencial é um processo contínuo que permite ao indivíduo o contato com novas experiências, transformando sua maneira de pensar. A aprendizagem é fundamentada nas experiências. A terceira premissa parte da ideia de que a aprendizagem experiencial requer uma resolução de conflitos, uma vez que ela descreve conflitos dialéticos entre concreto/abstrato, reflexão/ação. A quarta premissa envolve o processo holístico da aprendizagem experiencial. 0 ser humano aprende não apenas com formas tradicionais de sala de aula, mas com a experiência de mundo que adquire e o transforma. A aprendizagem experiencial passa a ser uma adaptação ao mundo. A quinta premissa guarda relações com a anterior e sugere que a aprendizagem envolve relacionamento entre o indivíduo e o ambiente. Kolb (1984) compreende esse processo como um entrelace entre o ser e o meio, de forma que esses dois elementos formam um novo. Por fim, o autor considera como sexta premissa a aprendizagem como o processo de criação de conhecimento. Kolb (1984) pontua que o conhecimento é resultado da transação entre o conhecimento pessoal e o conhecimento social. Para o autor, para que seja possível ocorrer a aprendizagem, é necessário entender o conhecimento humano e o processo pelo qual ele é criado. 0 processo de aprendizagem está relacionado com a transação entre objetivo e subjetivo, possuindo uma abordagem prática de resolução de conflitos, do senso comum e da interpretação em busca do conhecimento (KRAKAUER; SANTOS; ALMEIDA, 2017).

O Ciclo de Aprendizagem Experiencial de Kolb têm sido aplicado em estudos recentes de diversas áreas como gestão, saúde, computação e tecnologia, sociologia, psicologia, turismo, eletrônica, comunicação, entre outras (MCKINNEY, 2017; MOORHOUSE; JUNG, 2017; TOMKINS; ULUS, 2016; LI; ARMSTRONG, 2016; POORE; CULLEN; SCHAAR, 2014; KONAK; CLARK; NASEREDDIN, 2014), o que demonstra sua popularidade, mesmo em meio a críticas 
relativas à sua validade (BERGSTEINER; AVERY, 2014; AVERY; BERGSTEINER; NEUMANN, 2010).

De acordo com Morris (2019), o modelo de Kolb é, provavelmente, o modelo mais influente e citado de acordo com a teoria da aprendizagem experiencial, mas o autor critica o que Kolb chama de "experiência concreta" na aprendizagem, alegando que falta clareza na definição desse termo, crítica também feita por Bergsteiner e Avery (2014), que sustentam a ideia de que a literatura em aprendizagem tende a confundir classes importantes de modelos de aprendizagem (concreta, ativa, primária, abstrata, passiva, secundária).

Dessa forma, Morris (2019) desenvolveu revisão sistemática da literatura, com a finalidade de examinar o que seria essa experiência concreta. Por meio dessa análise, o autor identificou cinco temas: alunos envolvidos (ou ativos, ou participantes), conhecimento situado no lugar e no tempo, alunos expostos a novas experiências (fase que envolve risco), a exigência de investigação de problemas específicos do mundo real para se chegar ao aprendizado e reflexão crítica como mediador da aprendizagem.

Morris (2019) sugere uma revisão do modelo de Kolb da seguinte forma: experiência concreta contextualmente rica, observação reflexiva crítica, conceituação abstrata contextual específica e experimentação ativa pragmática. 0 autor reforça que ainda são necessários estudos empíricos para validar o modelo proposto.

Segundo Bergsteiner e Avery (2014), o modelo de Kolb tem sido criticado por diversos estudiosos por não prestar suficiente atenção à reflexão, diferenças de cultura, contexto, emoção, fundamento teórico do aprendiz, assimilação de informação e memorização, como os processos de aprendizagem se relacionam com o conhecimento e se a aprendizagem ocorre em etapas identificáveis.

No mundo ideal, a reflexão faz parte da rotina organizacional, porém Mintzberg (1990), em seus achados sobre mitos e verdades gerenciais, sugere que a figura do gerente como planejador sistemático e reflexivo é um mito. Em contraposição a essa figura, existe a realidade da não inclinação à reflexão por meio dos gerentes, devido ao seu ritmo de trabalho e suas atividades. Outras barreiras que podem ser vistas na organização, por exemplo, são a falta de tempo hábil para pensar, a visão de curto prazo sobre atividades, tarefas, prazos e o 
conflito com outras áreas dentro da organização (SILVA; ARAÚJO; CARRAZZONI, 2016; SILVA, 2018)

Segundo Roglio (2006), o pensamento reflexivo atua na capacidade de redefinir hipóteses/suposições. Sob esse prisma, Daudelin (1996), cujo estudo também emergiu dos achados de John Dewey, sugere que a reflexão pode ser considerada um elemento importante no alcance do aprendizado por meio da experiência. A partir desse entendimento, a autora descreve um fluxo de quatro estágios pelo qual o processo reflexivo passa. Em um primeiro momento, o indivíduo identifica uma situação problemática a qual deverá solucionar. Após esse estágio, é necessário analisar a situação e traçar as possibilidades para a resolução do problema. Em um terceiro momento, elege-se uma das possibilidades, elaborando-se uma hipótese que deverá ser sustentada levando em consideração o confronto entre seus pontos fortes e fracos, previamente discutidos com outros indivíduos. Por fim, a ação ocorre pautada na hipótese elegida como mais viável a ser aplicada.

Para Soares Neto (2010, p. 47) "refletir é agir, intelectualmente". Segundo Araújo et al. (2013) é notável a ação como um processo central nos estudos de Dewey (1959), Daudelin (1996) e Schön (2000). Porém, é possível observar que a ação é mais frequente no processo de reflexão sugerido por Schön (2000), gerando significados mais profundos ao praticante.

Para Dewey (1959), o pensamento pode ser considerado comum ou reflexivo. Partindo do conceito de pensamento reflexivo, Hatton e Smith (1995) sugerem quatro tipos de reflexão, tendo seus conceitos posteriormente desenvolvidos por meio do trabalho de Marcolino e Mizukami (2008).

A primeira delas é a reflexão escrita descritiva, que não necessariamente se caracteriza como reflexão disposta a modificar o curso da ação, mas ocorre por meio de uma narrativa, em que o indivíduo recorre ao relato de uma situação passada (MARCOLINO; MIZUKAMI, 2008). 
O segundo tipo de reflexão é denominado descrição reflexiva, que busca justificar ações ocorridas com base em julgamento pessoal. A reflexão dialógica diz respeito ao diálogo sobre determinada situação, em que se busca alternativas para explicar os fatos ocorridos. Por fim, a reflexão crítica, que pode gerar uma alteração na maneira como se entende determinada situação e consequentemente um questionamento sobre a essência de determinados eventos.

A terminologia reflexão crítica também é utilizada por Merizow (2000), que entende esse tipo de reflexão como baseada na avaliação de pressupostos provenientes de contextos culturais, sociais ou históricos. Stephen Brooksfield, em 1995, escreve um livro denominado Becoming a Critically Reflective Teacher, defende a importância de três premissas comuns a esse tipo de reflexão, citados por Merizow (2000): (1) premissas paradigmáticas, que estruturam a visão de mundo e, segundo o autor, o mais difícil de identificar em si mesmo; (2) pressupostos prescritivos, que diz respeito ao que pensamos que deveria estar ocorrendo em determinada situação e; (3) suposições causais - como o mundo funciona e como pode ser mudado, segundo o autor, o mais fácil de identificar.

Além dos tipos de reflexão defendidos por Hatton e Smith (1995), surge o conceito de autorreflexão crítica, em que o indivíduo se autoquestiona, enquanto ser social, sobre seus valores, crenças, atitudes (HOYRUP, 2004). Em contraste com essa ótica, Reis (2007) sugere que além da reflexão individual, existe a denominada reflexão pública ou organizacional, compartilhada por um determinado grupo, de caráter coletivo, não individual.

Assim como Dewey (1959), Seibert e Daudelin (1999) entendem reflexão como um exame cognitivo da experiência vivenciada pelo indivíduo, mais especificamente na atuação da prática gerencial. Para os autores, o indivíduo internaliza experiência do mundo externo, de forma a analisar essas situações, buscando entendimento sobre elas. Esse processo de reflexão gerencial foi dividido em dois aspectos: reflexão ativa e proativa.

Entende-se por processo reflexão ativa aquela que ocorre espontaneamente durante a jornada de experiências em que o gerente se coloca. Nesse caso, o indivíduo é posto em 
posição de desafio. 0 diálogo e interpretação sobre a situação em pauta gera a reflexão, por consequência um novo direcionamento sobre determinada situação. A reflexão proativa ocorre de maneira formal, de modo que só ocorre quando os indivíduos recebem a oportunidade de desenvolvê-la. Esse tipo de reflexão envolve a narrativa de uma situação pretérita, a fim de analisá-la de forma intencional, entendendo seu significado.

No contexto de uma organização ocorre o que Polanyi (1966) chama de socioprática, que é a interação entre indivíduos e suas práticas. Dessa forma, é possível sugerir que essa interação de indivíduos e práticas pode gerar novas construções de sentidos por meio das experiências vivenciadas no contexto organizacional e das reflexões sobre elas (WEICK, 1995; VILLARDI; VERGARA, 2011).

Segundo Silva, Larentis e Zanandréa (2019), de acordo com a perspectiva construtivista, há indícios na literatura de que a experiência não leva automaticamente à aprendizagem, sendo necessária a atuação reflexiva para gerar no indivíduo uma alteração de pensamento e comportamento. Por meio da reflexão sobre suas ações, o indivíduo poderá reconstruir e reorganizar as suas experiências (SILVA; LARENTIS; ZANANDRÉA, 2019).

A reflexão é o link necessário entre a experiência e a aprendizagem (PEKKOLA; HILDÉN; RÄMÖ, 2015). Segundo as autoras, nenhuma experiência leva automaticamente à aprendizagem, a não ser que haja uma reflexão sobre nossas próprias conclusões e suposições. Assim, a reflexão é necessária para que haja mudança de pensamento e comportamento.

Existe ainda uma diferença na literatura a respeito de dois tipos de aprendizagem que envolvem a reflexão: aprendizagem experiencial e aprendizagem reflexiva. Enquanto a aprendizagem experiencial existe um conjunto de tarefas e problemas complexos, requerendo experiências amplas e variadas, a aprendizagem reflexiva possibilita que o indivíduo trabalhe com experiência interna, refletindo sobre ela (SILVA; LARENTIS; ZANANDRÉA, 2019; MOON, 2013; ANTONELLO, 2011). 


\section{AS PROPRIEDADES DO SENSEMAKING NA APRENDIZAGEM EXPERIENCIAL}

Diante dos conceitos sobre sensemaking que circulam na literatura, Weick (1995) elenca sete propriedades visíveis nesse processo. Essas características fazem uma distinção mais clara entre o processo de sensemaking dos demais processos como entendimento, interpretação e atribuição. Segundo o autor, o sensemaking é: 1) fundamentado na construção da identidade; 2) retrospectivo; 3) criado em ambientes sensatos; 4) social; 5) dinâmico; 6) focado em e por dicas extraídas e 7) dirigido por plausibilidade em vez de acurácia e precisão.

Nessa seção, exploraremos como algumas dessas propriedades guardam relação com o processo de aprendizagem experiencial e de reflexividade, que está inserido no ciclo da aprendizagem experiencial. E também, como os conceitos de utilizados no modelo de organizing de Weick (1973) também guardam relação com os conceitos trabalhados em aprendizagem experiencial, pois se trata de um processo de entrada de informações, extração de ambiguidades e formação de novos padrões de comportamento dentro do ambiente, sendo, também, um processo cíclico, o qual veremos mais adiante.

Uma das propostas desse ensaio teórico é apontar semelhanças e inter-relações entre as duas teorias, com a finalidade de sugerir que o processo de sensemaking faz parte do Ciclo de Aprendizagem Experiencial apresentado por Kolb (1976), e, sobretudo, identificar como as propriedades do sensemaking estão acomodadas nesse processo. Sustentamos, portanto, que as teorias são construtos complementares. No entanto, para estabelecer essa correlação, destacamos a ênfase tanto no aspecto cognitivo do sensemaking, como também no aspecto construtivista social.

Segundo Dewey (1959), o indivíduo está acostumado a que as coisas tenham significados e, por causa disso, esquece que anteriormente as coisas que não existiam foram sugeridas por pensamentos já existentes que hoje fazem sentido; isso porque o pensamento 
reflexivo e a aprendizagem fazem parte da construção de sentido do indivíduo. Segundo Antonello e Godoy (2010), com base na teoria da construção social, a aprendizagem organizacional ocorre por meio de processos cognitivos que são socialmente mediados pela interpretação e pelo sensemaking. Segundo Reissner (2005), a aprendizagem se dá quando um novo sentido é formado pelos indivíduos por meio da reflexão e compartilhamento de experiências, sendo esse um processo contínuo. Maravalhas e Odelius (2010) estudaram acerca da aprendizagem e sensemaking em práticas de rotina de auditores e observaram que os participantes desconstruíram coletivamente aquilo que se tinha como conceito, por meio das práticas de rotina. As autoras sugerem que esse achado corrobora pressupostos da abordagem social da aprendizagem e atendem às propriedades do sensemaking.

Para Colville, Hennestad e Thorner (2014), a aprendizagem encontra-se no espaço entre a preocupação da ordem dos quadros de referência derivados dos momentos passados da organização e das pistas nas formas dos momentos atuais. Assim, as ideias e o processo de "tornar-se" estão no centro de uma maneira revisada de entender a aprendizagem no processo de sensemaking (COLVILLE; PYE; BROWN, 2016).

No processo de sensemaking, existe a figura do sensemaker, ou seja, a indivíduo que fará sentindo sobre alguma coisa. Tsoukas (2014) sugere que o sensemaker aprende por ficar em sintonia com o processo, não apenas prestando atenção no conteúdo (o que), mas prestando atenção ao processo de experimentar (como). Esse processo de primeira e segunda ordem, respectivamente, descobrir o que está acontecendo e o que será feito, são as questões nas quais o sensemaking gira em torno. Esse sensemaker tem a sua identidade construída a partir da interação com os demais indivíduos, o que caracterizará em uma identidade também coletiva. 0 processo de aprendizagem experiencial, segundo a teoria Kolbiana, também revela a interação entre indivíduos. Nem todas as experiências com as quais o indivíduo tem contato se transformarão em aprendizagem, mas existe um processo contínuo de ação e reflexão, sendo que, dentro da organização, essa aprendizagem pela experiência é geralmente compartilhada por outros atores envolvidos no mesmo ambiente. 
Com a dinamicidade vivida hoje nas organizações, novas informações adentram o seu ambiente (WEICK, 1973) e os indivíduos se deparam com situações que nunca experimentaram antes, sobretudo no ambiente organizacional. Duas das situações que geralmente ocorre com frequência em ambientes organizacionais saudáveis é a transmissão de conhecimento e a tomada de decisão. Esses conhecimentos são, muitas vezes, compartilhados por meio de histórias, metáforas, analogias, demonstrações, gerando reflexões sobre esses conhecimentos, sejam eles tácitos ou explícitos - a fim de que, futuramente, esse conhecimento seja aplicado por meio da ação (SILVA; LARENTIS, ZANANDRÉA, 2019; MOON, 2013; SNOWDEN, 2010). Essas situações podem e devem gerar aprendizado, a depender da maneira como são administradas. Segundo Silva (2009), indivíduos que compõem a organização são atores - agentes diretos ou indiretos - no processo de aprendizagem, pois fomentam a criação de visão compartilhada que norteia as ações pessoais num ambiente social. Ainda segundo o autor, o grupo também pode contribuir na geração de novos significados quando existe abertura para o diálogo, geração de ideias e inovação. Segundo Kolb (1984), o próprio conhecimento é também social, não existindo apenas em livros, mas requer uma aprendizagem interativa, a fim de que se possa compreender e interpretar símbolos. Para a teoria Kolbiana, o ser humano e o ambiente dialeticamente se transformam, mútua e reciprocamente, ou seja, a aprendizagem também é criada em ambientes sensatos, conforme sugere Weick (1995), quando afirma que as pessoas fazem parte dos seus próprios ambientes criados.

Conforme sugere Kolb (1976), o primeiro estágio da aprendizagem experiencial são as observações e reflexões. A partir desse estágio, ocorre a formação de conceitos abstratos e generalizações, posteriormente testadas em novas situações. 0 processo de reflexão modifica os quadros de referências dos indivíduos. Quando surgem os elementos-surpresa que desestabilizam esses quadros, ocorre o processo de reflexão, novos sentidos são gerados e postos em prática, até que esses novos estímulos sejam compreendidos e padronizados. Nesse ponto, surgem as novas práticas e o ciclo é novamente iniciado, conforme sugere Kolb (1984), é criado e recriado, portanto existe uma dinamicidade no processo, tal qual é encontrado no sensemaking. A dinamicidade é encontrada nos dois processos, e diz respeito a 
eventos em curso; o Ciclo de Aprendizagem, assim como o sensemaking, ocorre incessantemente, sendo que a cada momento em que novas observações e reflexões são feitas no início de um novo processo de aprendizagem, o processo de sensemaking também ocorre simultaneamente.

Quanto à fase de observações e reflexões no Ciclo de Aprendizagem de Kolb (1976), observamos a propriedade citada por Weick (1995) como extracted cues, ou dicas/referências que atuam na seleção e classificação de informações dos eventos em curso (MUNCK, 2015). 0 indivíduo possui a capacidade extrair e interpretar pistas ambientais para entender as ocorrências, entendendo da forma mais ampla o que pode estar acontecendo (WEICK, 1995; BROWN; COLVILLE, PYE, 2015). Nessa etapa, o indivíduo aprende observando o ambiente e extraindo dicas, interpretando-as e, posteriormente, utilizando a lógica e ideias, chega-se ao ponto de formar conceitos abstratos que serão testados numa próxima etapa (CERQUEIRA, 2008). É possível que essa propriedade seja necessária para que haja a seleção de informações e eventos que levarão o indivíduo à fase seguinte: a criação de conceitos.

$\mathrm{Na}$ fase de formação de conceitos abstratos e generalizações, fruto do processo de reflexividade, aspectos da identidade narrativa do sensemaker são alterados, pois um novo sentido está sendo construído (WEICK, 2005; MUNCK, 2015). Em conjunto a esse aspecto, podemos sugerir que a plausibilidade é outra propriedade encontrada nessa fase do ciclo. 0 indivíduo precisa ser capaz de criar conceitos que integrem suas observações de forma teoricamente lógica, portanto é necessário que haja plausibilidade, a fim de que ele consiga distorcer e filtrar as informações decidindo por aquelas que fazem sentido, descartando as que não fazem (WEICK, 2005; MUNCK, 2015).

A fase de experimentação ativa, quando o indivíduo está apto a usar as teorias para tomar decisões e resolver problemas envolve ações e discursos que são promulgados por aquele que está dentro do ciclo da aprendizagem. Inclusive, também nessa fase podemos perceber que o caráter social existente no sensemaking também está presente no Ciclo de Aprendizagem Experiencial. Nesse caso, o indivíduo tomará decisões e resolverá problemas 
dentro de um ambiente social organizacional, em que outros atores, ações, histórias, discursos e narrativas também são estão envolvidas. Além disso, como já dito anteriormente, para a Teoria Kolbiana o ser humano e o ambiente dialeticamente se transformam, mútua e reciprocamente, ou seja, a aprendizagem também é criada em ambientes sensatos.

Para Dewey (1959), a reflexividade trata-se de uma competência de caráter individual, cognitivo, e que não ocorre de maneira involuntária, mas é desencadeada a partir de algum elemento que envolva a perplexidade, confusão ou dúvida. 0 autor sugere que, a partir do momento em que surge uma dificuldade, imediatamente ocorre a sugestão de algum meio de sair dela. Essas sugestões vêm de dados que dispomos em nosso conhecimento por experiências passadas. Por meio dessa característica, durante o processo de sensemaking o indivíduo passa a refletir sobre a experiência vivenciada, trabalhando a reconstrução da sequência dos atos. Dessa forma, o mesmo caráter retrospectivo considerado no sensemaking também é visível no pensamento reflexivo, apesar de se tratarem de teorias distintas.

Para explicar a contraposição entre aprendizagem e desenvolvimento dentro do ciclo quadrifásico, Kolb (1976) explica dois conceitos: integração hierárquica e diferenciação crescente. A diferenciação ocorre em dois sentidos simultâneos: o aumento da complexidade do conhecimento, para a construção de uma só unidade, e a interdependência entre as suas partes. A diferenciação é a responsável pelo refinamento do conhecimento, enquanto a integração é caracterizada por uma escala hierárquica, organizada por elementos e atributos por categorias (PIMENTEL, 2007). No nível mais básico dessa escala, são elencadas regras simples e inflexíveis sobre as experiências como, por exemplo, sua classificação como boas ou ruins. No último nível, essas regras são mais complexas, propiciando maior flexibilidade à integração e diferenciação. Isso resulta na capacidade de lidar com mudanças e incertezas ambientais por meio do desenvolvimento de outras construções alternativas complexas sobre determinada realidade (KOLB, 1976; PIMENTEL, 2007).

Essa característica se relaciona com mais uma vez com uma propriedade do sensemaking: guiado por plausibilidade em vez de pela precisão. Weick, Sutcliffe e Obstfeld (2005) pontuam que sensemaking não é sobre uma verdade absoluta ou certeza, mas sobre 
um processo contínuo. A aprendizagem experiencial também se caracteriza como um processo contínuo que necessita lidar com mudanças e incertezas ambientais. Não existe uma verdade absoluta no processo de aprendizagem, podendo este ser revisto e modificado por meio de um novo ciclo envolvendo observações, reflexões, abstrações e experiências concretas.

O processo de sensemaking nas organizações, o Organizing, também guarda suas relações com Ciclo de Aprendizagem. Weick (1995; 2005) nos traz a visão de que a "organização" é resultado de um processo evolutivo de organizar e direcionar as raízes do processo de sensemaking, abrindo caminho para novos conceitos e entendimentos sobre como a organização é constituída (SANDBERG; TSOUKAS, 2015).

Antes de adentrar no modelo de Organizing proposto por Weick (1973) é importante ressaltar que, segundo o autor, o modelo é aplicável aos mais variados níveis hierárquicos de uma organização, também não sendo propriedade exclusiva de algum tipo organizacional.

Quadro 1. Conceitos do Modelo de Weick (1973)

\begin{tabular}{|c|c|}
\hline Ambiente & $\begin{array}{l}\text { Diz respeito às informações recebidas pelos atores na organização, a } \\
\text { partir das quais o indivíduo percebe algumas delas e passa a respondê- } \\
\text { las. } 0 \text { ambiente, nesse caso, não diz respeito às estruturas físicas também } \\
\text { encontradas na organização, mas a um ambiente abstrato de informações. } \\
\text { A organização busca sanar as ambiguidades existentes em informações } \\
\text { recebidas e que são consideradas relevantes (WEICK, 1973). }\end{array}$ \\
\hline Criação na ação & $\begin{array}{l}\text { A criação é o primeiro processo do modelo de Weick. Os membros da } \\
\text { organização não são meros agentes passivos no ambiente, mas participam } \\
\text { do processo de construção e nele fazem sentido. A partir do momento em } \\
\text { que novas informações passam a figurar nesse processo e os membros da } \\
\text { organização passam a fazer sentido delas, ocorre um novo processo de } \\
\text { mudanças no ambiente de informações, em que serão necessárias novas } \\
\text { regras e ciclos para processar a entrada de novas informações (WEICK, } \\
\text { 1973; MONTENEGR0, 2009). }\end{array}$ \\
\hline
\end{tabular}




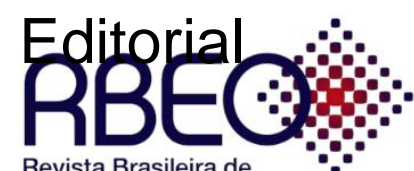

Revista Brasileira de

Estudos Organizacionais
Adrianne Garcia, Ludmilla Meyer Montenegro

FAÇO SENTIDO; LOGO, APRENDO: AS PROPRIEDADES DO SENSEMAKING NA APRENDIZAGEM EXPERIENCIAL

\begin{tabular}{|c|c|}
\hline Equivocidade & $\begin{array}{l}\text { A partir do momento em que ocorre a criação de um novo ambiente de } \\
\text { informações, o nível de equivocidade das novas entradas de informações } \\
\text { é determinado. A equivocidade diz respeito ao nível de equívoco presente } \\
\text { em determinada informação. É possível substituir esse termo por } \\
\text { "ambiguidade". O nível de equivocidade retrata o quanto de certeza ou } \\
\text { incerteza permeia diante de determinado cenário (WEICK, 1973). }\end{array}$ \\
\hline $\begin{array}{c}\text { Ciclos de } \\
\text { comportamentos } \\
\text { interligados }\end{array}$ & $\begin{array}{l}\text { Os comportamentos interligados são comportamentos repetitivos, } \\
\text { recíprocos e contingentes que são mantidos entre atores. A interação } \\
\text { entre esses atores caracteriza-se como uma troca, em que um ator usa } \\
\text { outro e por ele é usado para a realização de atividades que não seriam } \\
\text { realizadas por si só. A partir dessa interação, os ciclos de } \\
\text { comportamentos interligados tendem a afastar determinada } \\
\text { ambiguidade, mas esse processo torna-se mais efetivo a medida em que } \\
\text { são aplicados ciclos diferentes à informação para que se possa chegar a } \\
\text { um grau satisfatório de certeza (WEICK, 1973). }\end{array}$ \\
\hline Regras & $\begin{array}{l}\text { As regras desempenham duas funções: (1) averiguar o nível de } \\
\text { equivocidade ou familiaridade das mensagens que entraram no ambiente; } \\
\text { (2) buscar respostas de mensagens padronizadas disponíveis na } \\
\text { organização que condizem com as entradas específicas da mensagem. As } \\
\text { regras fazem a reunião do processo por meio do conjunto de ciclos } \\
\text { interligados que estão disponíveis na organização. A partir desse } \\
\text { processo, é escolhido um subconjunto para ser aplicado à informação em } \\
\text { questão (WEICK, 1973; MONTENEGRO; CASALI, 2008). }\end{array}$ \\
\hline Seleção & $\begin{array}{l}\text { Trata-se do segundo processo do modelo de Weick. A maior parte da } \\
\text { ambiguidade é afastada nesse processo, tendo em vista tratar-se do } \\
\text { conjunto de regras e ciclos considerados relevantes para a inserção no } \\
\text { processo. Nessa fase, são analisadas quais as regras e ciclos têm afetado o } \\
\text { nível de equivocidade na entrada de informações. Faz-se a opção por } \\
\text { quais ciclos serão mantidos (escolhidos) pela organização para dar } \\
\text { continuidade ao processo de futuras entradas de informações (WEICK, } \\
\text { 1973; MONTENEGRO; CASALI, 2008). }\end{array}$ \\
\hline
\end{tabular}




\begin{tabular}{|c|c|}
\hline Retenção & $\begin{array}{l}\text { A retenção apresenta-se como último processo do modelo. Nesse ponto, } \\
\text { são examinadas a quantidade de ambiguidade contida nas informações } \\
\text { em que o processo atua. A partir dessa informação, são avaliadas as } \\
\text { formas como a organização responde a diferentes entradas de informação } \\
\text { e a utilidade de determinados ciclos nesse processo. Os ciclos que são } \\
\text { considerados estratégias bem-sucedidas da mitigação de ambiguidade } \\
\text { são incorporadas como regras para servirem como respostas a entradas } \\
\text { de informações similares no futuro (WEICK, 1973; MONTENEGRO; } \\
\text { CASALI, 2008). }\end{array}$ \\
\hline $\begin{array}{c}\text { Feedback loops } \\
\text { (retroalimentação) }\end{array}$ & $\begin{array}{l}\text { Essa parte do processo está baseada no sucesso das etapas anteriores. } \\
\text { Esse feedback permite conectar as três fases do processo, que, ao chegar } \\
\text { ao final, será retroalimentado, pois armazena informações sobre as } \\
\text { mensagens criadas para posterior utilização (WEICK, 1973; } \\
\text { MONTENEGRO, 2009). }\end{array}$ \\
\hline
\end{tabular}

Fonte: elaborado pelas autoras com base no referencial teórico (WEICK, 1973; MONTENEGRO; CASALI, 2008; MONTENEGRO, 2009).

Weick (1973) argumenta que uma organização pode ser definida pelos processos que a representa. 0 ponto principal dessa tese defendida pelo autor é que qualquer organização é a maneira pela qual ela passa pelos processos que a formam. 0 ambiente organizacional é produto da criação dos próprios atores, quem recebem informações, fazem sentido sobre elas, afastam suas ambiguidades e geram ações já finalizadas. Para Weick (1973), a organização é o conjunto de atividades desenvolvidas pelos seus membros, fruto da compreensão do ambiente em que está inserido.

O modelo de Organizing construído por Weick evidencia uma série de processos cuja finalidade é afastar as ambiguidades inerentes às informações chegadas ao ambiente organizacional, de forma que essas informações possam ter o seu sentido compartilhado na organização. Três processos centrais permeiam o modelo: criação na ação (enactment), seleção e retenção. Além dos processos principais, cada processo contém um conjunto de subprocessos: regras de reunião, ciclo de comportamento e o afastamento da ambiguidade. 
Para que haja o afastamento da ambiguidade organizacional, anteriormente é necessário um registro dessa ambiguidade, conforme ilustra o modelo abaixo:

Figura 2. Modelo de organizing de Weick (1979)

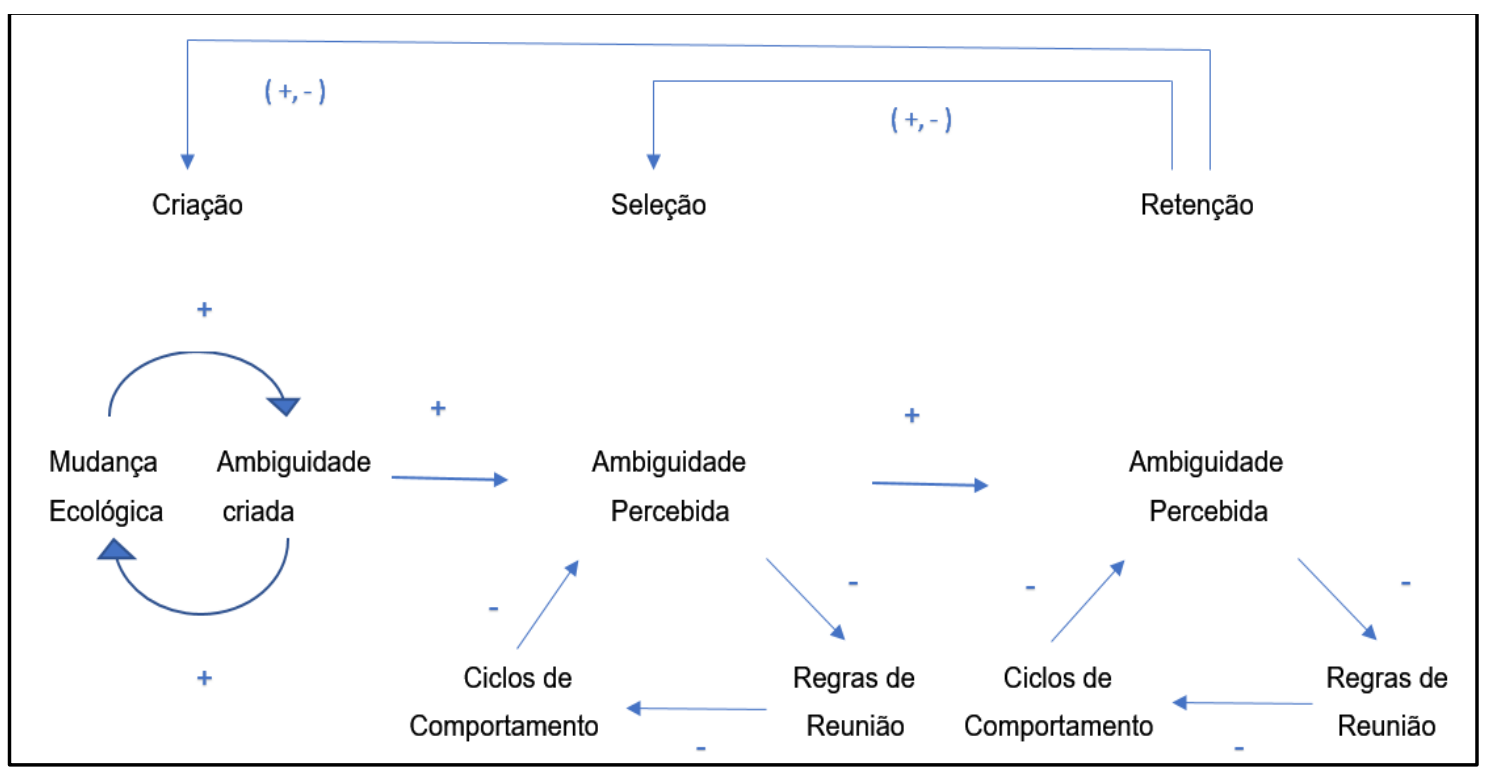

Fonte: Adaptado de Weick (1979, p.133).

O processo inicia-se a partir de uma mudança no ambiente (mudança ecológica), em decorrência de uma informação externa a ele. Vale ressaltar, como pode ser visto no ciclo, que informações internas também retroalimentam o processo. Portanto, tanto informações alheias ao ambiente quanto informações integrantes do ambiente influem no processo de criação e seleção. Essa retroalimentação é representada pelas linhas existentes entre esses processos (WEICK, 1973).

Esses dois processos supracitados diferem da seguinte forma: enquanto na criação os indivíduos agem, fazem, realizam algo, na seleção eles fazem escolhas. Essas escolhas são baseadas na etapa anterior, pois os atores optam por selecionar as ações que geraram melhor resultado, sendo suas experiências consideradas benéficas (WEICK, 1973). 
Mesmo as informações repassadas de um ciclo para outro ainda contêm determinado grau de ambiguidade. Quando essas informações adentram no ciclo, é necessário o registro do grau de ambiguidade nela existente. Esse registro é feito por meio do número de regras de reunião que são determinadas para a composição do processo. A relação entre ambiguidade e regras de reunião é inversa. Se existem muitas regras para líder com determinado aspecto do ambiente, então o nível de ambiguidade da informação é baixo, e vice-versa. Caso o ambiente se depare com uma situação em que não existem muitas regras aplicadas ao caso, então existe um alto grau de ambiguidade nessa informação. Por outro lado, existe uma relação diretamente proporcional no que fiz respeito às informações e processos. Se uma informação tem um alto grau de ambiguidade, o processo tende a ter menos regras, então o processo também possui um alto grau de ambiguidade (WEICK, 1973).

Após a maior parcela de ambiguidade ser afastada no processo de seleção, ela segue para o processo final de retenção. Como o próprio nome já diz, nesse processo a informação é retida, armazenada, mas também gera a redução de ambiguidade por passar novamente por um ciclo em que são integradas novas informações e interpretações. Nesse ponto, são examinadas a quantidade de ambiguidade contida nas informações em que o processo atua. A partir dessa informação, são avaliadas as formas como a organização responde a diferentes entradas de informação e a utilidade de determinados ciclos nesse processo. Os ciclos que são considerados estratégias bem-sucedidas da mitigação de ambiguidade são incorporadas como regras para servirem como respostas a entradas de informações similares no futuro (WEICK, 1973; MONTENEGRO; CASALI, 2008).

É possível observar os feedbacks loops entre retenção e criação e retenção e seleção. 0 processo de retroalimentação entre retenção e criação decorre da utilização das informações retidas em processos anteriores para servir de guia na avaliação de mensagens futuras no ambiente. No tocante ao processo de retroalimentação entre retenção e seleção, as informações retidas servem como guia para a decisão de como processar futuras entradas de informação baseando-se na inteligência organizacional e no repertório de regras armazenadas nessa fase (MONTENEGRO; CASALI, 2008). 
O processo de entrada de informações, extração de ambiguidades e formação de novos padrões de comportamento dentro do ambiente é um conjunto de tarefas que opera de forma cíclica, tal qual o Ciclo de Aprendizagem Experiencial. 0 organizing é um processo de sensemaking, portanto, incorpora também todas as propriedades já citadas anteriormente.

A capacidade de observar e refletir é inerente tanto ao Ciclo de Aprendizagem quanto ao processo de organizing. Essas características cognitivas e também sociais estão presentes em ambos os processos, gerando novas identidades no ambiente organizacional por meio de sentidos (entendidos, nesse caso, como percepções geradas por meio de reflexões).

Quanto ao organizing, enquanto na criação os indivíduos agem, fazem, realizam algo, na seleção eles fazem escolhas, como já citamos anteriormente. Agir, realizar, fazer escolhas são aspectos sociais que ocorrem nesse processo e também no Ciclo de Aprendizagem, mais especificamente na experimentação ativa.

No organizing, os ciclos que são considerados estratégias bem-sucedidas da mitigação de ambiguidade são incorporadas como regras para servirem como respostas a entradas de informações similares no futuro, já no Ciclo de Aprendizagem, o indivíduo pode mergulhar na experiência completa, e sem vieses (ou seja, sem ambiguidades), e posteriormente dando início a novas experiências. Ambos os ciclos se repetem a cada entrada de novas informações.

\section{CONCLUSÕES}

0 presente estudo teve como objetivo de entender como a reflexividade e a aprendizagem experiencial se relacionam ao processo de sensemaking em suas sete propriedades elencadas por Weick (1995). Esse ensaio teórico buscou introduzir a discussão sobre a estreita relação existente entre aprendizagem, reflexividade e as propriedades do sensemaking, ainda pouco discutida em ambas as literaturas. 
As propriedades do sensemaking elencadas por Weick (1995) podem ser encontradas no Ciclo de Aprendizagem Experiencial proposto por Kolb (1984). 0 autor busca integrar em uma teoria aspectos de teorias cognitivistas e comportamentais, trazendo como centro da aprendizagem a experiência. Assim, ao fazê-lo, a teoria Kolbiana interpreta o ser e o meio em que está inserido como dois elementos essenciais para que haja a aprendizagem. As experiências desse ambiente geram o conhecimento, que é dinâmico, e o Ciclo de Aprendizagem, contínuo. O indivíduo faz sentido de tudo o que aprende por meio da experiência, percebendo pistas, fazendo interpretações e se engajando em ação (MAITLIS; CHRISTIANSON, 2014).

É possível enxergar o processo de sensemaking e suas propriedades permeando o processo de aprendizagem experiencial. O Ciclo de Aprendizagem Experiencial de Kolb (1984) traz quatro estágios da aprendizagem, em que é possível perceber diferentes estilos e momentos nesse processo: a experiência concreta, observações e reflexões, formação de conceitos abstratos e o teste de hipóteses e conceitos em novas situações. O indivíduo faz sentido na nova experiência no processo de aprendizagem, de forma que, após o teste de hipóteses e conceitos novas situações um novo sentido é construído.

Concluímos que o processo de sensemaking e o Ciclo de Aprendizagem Experiencial são semelhantes e complementares, e, dessa forma, é possível encontrar as propriedades do sensemaking também no Ciclo de Aprendizagem. Sustentamos que a aprendizagem experiencial é, também, uma forma de sensemaking, concordando com Reissner (2005).

Além disso, observamos e concluímos que há semelhanças também entre o modelo Organizing sugerido por Weick (1973) e o Ciclo de Aprendizagem Experiencial de Kolb (1976), principalmente nas fases em que envolve observação, reflexão, criação e seleção. É possível perceber a recorrência dessas atividades em ambos os ciclos, em suas fases específicas. Também concluímos que pelo fato de os processos de sensemaking e aprendizagem experiencial serem semelhantes e complementares, encontramos as propriedades do sensemaking elencadas por Weick (1995) também na aprendizagem experiencial. 
Esse estudo contribui para a área de estudos organizacionais, sobretudo para a literatura em aprendizagem experiencial e sensemaking, tendo em vista que reforça não só a semelhança e complementaridade das teorias, mas como as suas propriedades e características estão presentes uma na outra, sendo também compartilhadas. Além disso, o presente estudo traz críticas levantadas por estudiosos do sensemaking, que podem ser potencialmente trabalhadas em estudos futuros, também vinculados à questão da aprendizagem.

Como limitações de pesquisa, o presente ensaio teórico se ateve ao Ciclo de Aprendizagem de Kolb (1976) e à perspectiva de Sensemaking de Weick (1995), não explorando à fundo outras teorias e perspectivas. Desse modo, gera-se um gap em relação a ciclos de aprendizagem.

Para pesquisas futuras, sugerimos relacionar outras teorias de aprendizagem ao processo de sensemaking. Sugerimos, também, a construção de uma pesquisa bibliométrica e uma revisão sistemática da literatura em sensemaking e aprendizagem experiencial, a fim de levantar os estudos mais relevantes feito na área nos últimos anos, além de apontar semelhanças e divergências entre as teorias, e direções para futuras pesquisas empíricas. Além disso, sugerimos o desenvolvimento de pesquisas empíricas que explorem as propriedades do sensemaking elencadas por Weick (1995) no processo de aprendizagem, bem como em outras áreas, como práticas estratégicas e eventos que envolvam mudanças organizacionais.

\section{REFERÊNCIAS}

ANTONELLO, C.S. Saberes no singular? Em discussão a falta fronteira entre aprendizagem formal e informal. Aprendizagem organizacional no Brasil. Porto Alegre: Artmed, 2011.

ANTONELLO, C. S.; GODOY, A. S. A encruzilhada da aprendizagem organizacional: uma visão multiparadigmática. Revista de Administração Contemporânea, Curitiba, v. 14, n. 2, p. 310332, mar./abr. 2010. 
ARAÚJO, G.; SILVA, A.; LIMA, T.; BISPO, A. O desenvolvimento do pensamento reflexivo no curso de administração da universidade federal da paraíba. Revista Reflexão e Ação, Santa Cruz do Sul, v.21, n. esp., p.149-176, jul./dez. 2013.

ARRUDA, F.; ROSSONI, L. Esquemas Interpretativos e Respostas Estratégicas de Pequenos Empreendimentos em Favelas Cariocas Pacificadas. In: ANPAD, 2015. Anais... Rio de Janeiro: ANPAD, 2015.

ASMUß, B. Strategy as Practice. The International Encyclopedia of Strategic Communication, p. 1-5, 2018.

BAUER, M. A. L.; MESQUITA, Z. As concepções de identidade e as relações entre indivíduos e organizações: um olhar sobre a realidade da agricultura ecológica. RAC-Eletrônica, v. 1, n. 1, p. 16-30. 2007.

BERGER, P. L.; LUCKMANN, T. Construção Social da Realidade. Petrópolis: Vozes, 2010.

BROWN, A. D.; COLVILLE, I.; PYE, A. Making sense of sensemaking in organization studies. Organization Studies, v. 36, n. 2, p. 265-277, 2015.

BURRELL, G.; MORGAN, G. Sociological paradigms and organizational analisys. London: Heinemann, 1979.

CANABARRO, J.; SALVAGNI, J. Mulheres líderes: as desigualdades de gênero, carreira e família nas organizações de trabalho. Revista de Gestão e Secretariado, v. 6, n. 2, p. 88-110, 2015.

CERQUEIRA, Teresa Cristina Siqueira. Estilos de aprendizagem de Kolb e sua importância na educação. Journal of Learning Styles, v. 1, n. 1, 2008.

CHATMAN, J.; BELL, N.; STAW, B. The managed thought: The role of self-justification and impression management in organizacional setting. In Gioia, D.; Sims, H. The thinking organization: Dynamics of social cognition. CA: Jossey-Bass, p. 191-214. 1986.

CORNELISSEN, J. P.; SCHILDT, H. Sensemking in strategy as practice: a phenomenon or a perspective? In: SEIDL, D.; BAGOLUN, J.; VARA, E.; GOLSORKHI, D. (Eds.). Cambridge handbook on strategy as practice. 2. Ed. Oxford University Press, 2015, p.345-364.

CORREIA-LIMA, B. C.; RIGO, A. S.; SANTOS, M. E. P. D. Memória organizacional e construção de identidade local: uma análise da mobilização e organização social no Conjunto Palmeira. Administração Pública e Gestão Social, v. 8, n. 4, p. 235-246. 2016.

DAFT, R. L; WEICK, K. E. Toward a model of organizations as Interpretation systems. Academy of Management Review, v.9, n.2, p.284-295. 1984. 
DAUDELIN, M. W. Learning from experience through reflection. Organizational Dynamics, v. 24, n.3, p. 36-49. 1996.

DECKER, C. A. Sensemaking in organizations. Human Resource Development Quarterly, v. 9, n. 2, p. 198, 1998.

DEWEY, J. Art as experience. 1. Ed. New York: Putnam, 1934.

DEWEY, J. Vida e Educação. 3. Ed. São Paulo: Edições Melhoramentos, 1952.

DEWEY, J. Como pensamos: como se relaciona o pensamento reflexivo com o processo educativo. 4. ed. Tradução de Haydée Camargo Campos. São Paulo: Nacional, 1959.

DEWEY, J. Experiência e Educação. 2. Ed. São Paulo: Editora Nacional, 1976.

DEWEY, J. Democracia e Educação: Introdução à Filosofia da Educação. 4. Ed. São Paulo: Editora Nacional, 1979.

EINOLA, S.; KOHTAMÄKI, M.; PARIDA, V.; WINCENT, J. Retrospective relational sensemaking in R\&D offshoring. Industrial Marketing Management, 63, 205-216, 2017.

GIDDENS, A. A constituição da sociedade. São Paulo: Martins Fontes, 2009.

GIOIA, D.; CHITTIPEDDI, K. Sensemaking and sensegiving in strategic change initiation. Strategic Management Journal, v. 12. 1991.

GIOIA, D..; MEHRA, A. Sensemaking in organizations-Weick, KE. 1996.

GRAND, S.; ARX, W.; RÜEGG-STÜRM, J. Constructivist paradigms: implications for strategy-aspractice research. In: GOLSORKHI, D. et al; (2 Ed.). The Cambridge Handbook on Strategy as Practice. Cambridge, UK: Cambridge University Press, 2015. p. 129-151.

GOFFMAN, E. A representação do eu na vida cotidiana. 8 ed. Petrópolis, Vozes, 1999.

HATTON, N.; SMITH, D. Reflection in teacher education: Towards definition and implementation, Teaching and Teacher Education, v. 11, n. 1, p. 33-49, jan. 1995.

HILDEN, S.; TIKKAMÄKI, K. Reflective practice as a fuel for organizational learning. Administrative sciences, n. 3, v. 3, p. 76-95, 2013.

HOYRUP, S. Reflection as a core process in organisational learning. Journal of Workplace Learning, v. 7-8, n. 16, p. 442-454. 2004. 
JALONEN, K.; SCHILDT, H.; VAARA, E. Strategic concepts as micro-level tools in strategic sensemaking. Strategic Management Journal, v. 39, n. 10, p. 2794-2826, 2018.

JARZABKOWSKI, P.; SPEE, A. Strategy-as-practice: A review and future directions for the field. International journal of management reviews, v. 11, n. 1, p. 69-95, 2009.

JEONG, HS; BROWER, R.. Extending the present understanding of organizational sensemaking: Three stages and three contexts. Administration \& Society, v. 40, n. 3, p. 223-252, 2008.

JORDI, R. Reframing the concept of reflection: Consciousness, experiential learning, and reflective learning practices. Adult Education Quarterly, 0741713610380439, 2010.

GOMES, J. O.; FANTINEL, L. D.; PALASSI, M. P.; SILVA, A. R. L. Identificação e alteridade na identidade organizacional de uma organização pública. Administração Pública e Gestão Social, v. 8, n. 4, 2016.

KOLB, D. A. Management and the Learning Process. California Management Review, v.38, n.3, p.21-31, Spring, 1976.

KOLB, D. A. Experiential learning: experience as the source of learning and development. New Jersey: Prentice Hall, 1984.

KONAK, A.; CLARK, T. K.; NASEREDDIN, M. Using Kolb's Experiential Learning Cycle to improve student learning in virtual computer laboratories. Computers \& Education, v. 72, p. 11-22, 2014.

KUZNETSOV, A; KUZNETSOVA, O. Building professional discourse in emerging markets: Language, context and the challenge of sensemaking. Journal of International Business Studies, v. 45, n. 5, p. 583-599, 2014.

LI, M.; ARMSTRONG, S. J. The relationship between Kolb's experiential learning styles and Big Five personality traits in international managers. Personality and Individual Differences, $\mathrm{v}$. 86, p. 422-426, 2015.

LOUIS, M. Suprise and Sensemaking: What Newcomers Experience Entering Unfamiliar Organizational Settings. Administrative Science Quarterly, p.226-251. 1980.

MACHADO-DA-SILVA, C.; FERNANDES, B. H. R. O impacto da internacionalização nos esquemas interpretativos dos dirigentes do Banco Bamerindus. Revista de Administração de Empresas, v. 39, n. 1, p. 14-24. 1999.

MACHADO-DA-SILVA.; C.; FONSECA, V.; CRUBELLATE, J. M. Estrutura, agência e interpretação: elementos para uma abordagem recursiva do processo de institucionalização. Revista de Administração Contemporânea, 1a ed. esp., v. 9, p. 9-39. 2005. 
MACLEAN, M.; HARVEY, C.; CHIA, R. Sensemaking, storytelling and the legitimization of elite business careers. Human Relations, v. 65, n.1, p. 17-40, 2012a.

MAGALA, S. J. Book Review Essay: Karl E. Weick: Sensemaking in Organizations: 1995, London: Sage. 231 pages. Organization Studies, v. 18, n. 2, p. 317-338, 1997.

MAITLIS, S.; CHRISTIANSON, M.; Sensemaking in Organizations: Taking Stock and Moving Forward. The Academy of Management Annals, v. 8, n. 1, p. 57-125, jan. 2014.

MARCOLINO, T. Q.; MIZUKAMI, M.G.N. Narratives, reflective processes and professional practice: contributions towards research and training. Interface - Comunicação, Saúde, Educação, v.12, n.26, p.541-7, jul./set. 2008.

MARSICK, V. Experience-based learning: executive learning outside the classroom. Journal of Management Development, v. 9, n. 4, p. 50-60, 1990.

MCGILL, I.; BROCKBANK, A. The Action Learning Handbook: Powerfull Tecniques for education, professional development and training. RoutledgeFalmer. New York, 2004.

MCKINNEY, E. Using Kolb's Experiential Learning Cycle to lead students in learning about sewable circuits. 2017.

MEZIROW, J. Learning as transformation: critical perspectives on a theory in progress. San Francisco, CA: Jossey-Bass, 2000.

MILLS, J. H.; THURLOW, A.; MILLS, A. J. Making sense of sensemaking: the critical sensemaking approach. Qualitative Research in Organizations and Management: An International Journal, v. 5, n. 2, p. 182-195, 2010.

MILLS, J. H.; WEATHERBEE, T. G. Hurricanes hardly happen: Sensemaking as a framework for understanding organizational disasters. Culture and Organization, v. 12, n. 3, p. 265-279, 2006.

MINTZBERG, Henry. The design school: reconsidering the basic premises of strategic management. Strategic management journal, v. 11, n. 3, p. 171-195, 1990.

MONTEIRO, D. F. B.; PEREIRA, V. F.; OLIVEIRA, L. L.; LIMA, O. P.; CARRIERI, A. P. O Trabalho Sujo com a Morte: o Estigma e a Identidade no Ofício de Coveiro. Revista Interdisciplinar de Gestão Social, v. 6, n. 1, p. 77-98, 2017.

MONTENEGRO, L. M. Construção de sentidos (sensemaking) em práticas de um processo estratégico: Um estudo comparativo em duas instituições de ensino superior do Estado do Paraná. 207f. Dissertação (Mestrado) - Programa de Pós-Graduação em Administração da Universidade Federal do Paraná, Curitiba, 2009. 
MONTENEGRO, L. M.; CASALI, A. O Modelo de Organizing de Karl Weick e sua Ênfase na Comunicação. In: Encontro de Estudos Organizacionais da ANPAD, n. 5, p. 01-14, 2008.

MOON, J. A. Reflection in learning and professional development: Theory and practice. Routledge, 2013.

MOORHOUSE, N.; JUNG, T. Augmented reality to enhance the learning experience in cultural heritage tourism: An experiential learning cycle perspective. eReview of Tourism Research, v. 8, 2017.

MORRIS, T. H. Experiential learning-a systematic review and revision of Kolb's model. Interactive Learning Environments, p. 1-14, 2019.

MOTA-SANTOS, C.; CARVALHO NETO, A.; OLIVEIRA, P.; ANDRADE, J. Reforçando a contribuição social de gênero: a servidora pública qualificada versus a executiva. Revista de Administração Pública, v. 53, n. 1, p. 101-123, 2019.

MOURA, R. G.; NASCIMENTO, R. P.; BARROS, D. F. O Problema Não É Ser Gay, É Ser Feminino: O Gay Afeminado E As Organizações. Farol-Revista de Estudos Organizacionais e Sociedade, v. 4, n. 11, p. 1478-1541, 2017.

MUNCK, L. Gestão da sustentabilidade em contexto organizacional: Integrando sensemaking, narrativas e processo decisório estratégico. Organizações \& Sociedade, v. 22, n. 75, p. 521538, 2015.

NICOLINI, A. Qual será o futuro das fábricas de administradores? RAE - Revista de Administração de Empresas, v. 43, n. 2, p. 44-54. 2003.

O'CONNELL, D. Sensemaking in organizations. Administrative Science Quarterly, v. 43, n. 1, p. 205, 1998.

PEKKOLA, S.; HILDÉN, S; RÄMÖ, J. A maturity model for evaluating an organisation's reflective practices. Measuring Business Excellence, v. 19, n. 4, p. 17-29, 2015.

PEREIRA, B.; LOBLER. M.; SIMONETTO, E. Análise dos modelos de tomada de decisão sob o enfoque cognitivo. Revista de Administração da UFSM, Santa Maria, v.3, n.2, p. 260-268, mai./ago. 2010.

PIMENTEL, Alessandra. A teoria da aprendizagem experiencial como alicerce de estudos sobre desenvolvimento profissional. Estudos de psicologia, v. 12, n. 2, 2007.

PIMENTEL, T. D.; CARRIERI, A. P. A espacialidade na construção da identidade. Cadernos EBAPE.BR, v. 9, n. 1, art. 1, p. 1-21. 2011. 
POLANYI, M. The logic of tacit inference. The Journal of The Royal Institute of Philosophy, Cambridge, v. 41, n. 155, p. 1-18, jan. 1966.

POORE, J. A.; CULLEN, D. L.; SCHAAR, G. L. Simulation-based interprofessional education guided by Kolb's experiential learning theory. Clinical Simulation in Nursing, v. 10, n. 5, p. e241-e247, 2014.

POSSAS, M. de C; MEDEIROS, C. R. de O. SENSEMAKING EM CENA: COMPREENDENDO A CRIAÇÃO DE SENTIDO NO GRUPO GALPÃO DE TEATRO. Gestão \& Planejamento-G\&P, v. 17, n. 2, 2016.

PULLEN, A. THANEM, T.; TYLER, M.; WALLENBERG, L. Sexual politics, organizational practices: Interrogating queer theory, work and organization. Gender, Work and Organization, v. 23, n. 1, p. 1-6, 2016.

RAELIN, J. Public reflection as a basis of learning. Management Learning, v.32, n.1, p. 11-30. 2001.

REIS, D. 0 papel da reflexão na aprendizagem organizacional. 2007. 260 f. Dissertação (Mestrado em Administração) - Universidade Presbiteriana Mackenzie, São Paulo, 2007.

ROBICHAUD, D.; GIROUX, H; TAYLOR, J. R. The metaconversation: The recursive property of language as a key to organizing. Academy of Management Review, v. 29, n. 4, p. 617-634, 2004.

ROGLIO, K. D. O executivo reflexivo: arquiteto e facilitador de novas configurações organizacionais. 275 f. Tese (Doutorado em Engenharia de Produção) - Universidade Federal de Santa Catarina, Florianópolis, 2006.

ROULEAU, L; BALOGUN, J. Middle managers, strategic sensemaking, and discursive competence. Journal of Management studies, v. 48, n. 5, p. 953-983, 2011.

RUMENS, N.; SOUZA, E. M.; BREWIS, J. Queering queer theory in management and organization studies: notes toward queering heterosexuality. Organization Studies, v. 40, n. 4, p. 593-612, 2019.

SANDBERG, J.; TSOUKAS, H. Making sense of the sensemaking perspective: Its constituents, limitations, and opportunities for further development. Journal of Organizational Behavior, v. 36, n. S1, p. S6-S32, 2015.

SANTOS, F. P.; DAVEL, E. Gestão de Equipamentos Culturais e Identidade Territorial: Potencialidades e Desafios. Pensamento \& Realidade, v. 33, n. 1, p. 109-134, 2018. 
SARAIVA, L.; CARRIERI, A; SOARES, A. Territorialidade e identidade nas organizações: o caso do Mercado Central de Belo Horizonte. RAM. Revista de Administração Mackenzie, v. 15, n. 2, p. 97-126, 2014.

SCHÖN, D. A. Educando o profissional reflexivo: um novo design para o ensino e a aprendizagem. Porto Alegre: Artmed, 2000.

SEIBERT, K. W.; DAUDELIN, M.W. The role of reflection in managerial learning: theory, research and practive. Westport - London: Quorum, 1999.

SILVA, A. D. Como os gerentes aprendem?. São Paulo: Saraiva, 2009.

SILVA, A. G. C. A reflexividade e a aprendizagem no processo de sensemaking de práticas estratégicas: estudo de casos múltiplos em empresas juniores de Sergipe. Dissertação (Mestrado em Administração) - Programa de Pós-graduação em Administração, Universidade Federal de Sergipe. São Cristóvão, p.205. 2018.

SILVA, E. R.; LARENTIS, F.; ZANANDRÉA, G. Reflexão e Experiência: Elos para Storytelling e Aprendizagem Organizacional. Revista de Administração FACES Journal, v. 18, n. 1, p. 91110, 2019.

SILVA, A. B.; ARAÚJO, G. D.; CARRAZZONI, M. D. O Processo de Reflexão no Contexto da Ação: A Percepção de Executivos e Empreendedores. Revista Eletrônica de Estratégia \& Negócios, v. 9, n. 3, p. 154-181. 2016.

SOARES NETO, A. Aprendizagem de auditores fiscais no contexto da prática profissional. 2010. 166f. Dissertação (Mestrado) - Universidade Federal da Paraíba, João Pessoa, 2010.

SOUZA, E. M. A teoria queer e os estudos organizacionais: revisando conceitos sobre identidade. RAC-Revista de Administração Contemporânea, v. 21, n. 3, p. 308-326, 2017.

SNOWDEN, D. Naturalizing sensemaking. Informed by knowledge: Expert performance in complex situations, 223-234, 2010.

STARBUCK, W., MILLIKEN, F. Executives' perceptual filters; what they notice and how they make sense. In Executive Effect: Concepts and Methods for Studying Top Managers, ed. D. Hambrick. Greenwich, Conn: JAI In press, 1988.

STEIN, E. W. Organizational Memory: review of concepts and recommendations for management. International Journal of Information Management, v.15, n. 1, p. 17-32. 1995.

SCHWANDT, D. R. When managers become philosophers: Integrating learning with sensemaking. Academy of Management Learning \& Education, v. 4, n. 2, p. 176-192, 2005. 
TAYLOR, J. R.; VAN EVERY, E. J. The situated organization: Case studies in the pragmatics of communication research. Routledge, 2010.

TEIXEIRA, J. C.; SARAIVA, L. A. S; CARRIERI, A. P. Os lugares das empregadas domésticas. Organizações \& Sociedade, v. 22, n. 72, p. 161-178, 2015.

THOMPSON, E. Mind in life. MA: Harvard University Press, Cambridge. 2007.

TOMKINS, L.; ULUS, E. 'Oh, was that “experiential learning”?!'Spaces, synergies and surprises with Kolb’s learning cycle. Management Learning, v. 47, n. 2, p. 158-178, 2016.

VAARA, E.; WHITTINGTON, R. Strategy-as-practice: Taking social practices seriously. The Academy of Management Annals, v. 6, n. 1, p. 285-336, 2012.

VILLARDI; B.; VERGARA, S. Implicações da Aprendizagem Experiencial e da reflexão pública para o ensino de pesquisa qualitativa e a formação de mestres em administração. Revista de Administração Contemporânea, v. 15, n. 5, p. 794- 814. 2011.

WEICK, K. E. A Psicologia Social da Organização. São Paulo: Edgar Blucher: EDUSP. 1973.

WEICK, K. The Social Psychology of Organizing. 2 ed. Massachusetts: Addison-Wesley. 1979.

WEICK, K. E. Sensemaking in organizations. Thousand Oaks: Sage Publications. 1995.

WEICK, K; SUTCLIFFE, M.; OBSTFELD, D. Organizing and the Process of Sensemaking. Organization Science, v. 16, n. 4, jun/aug. 2005.

WHITTINGTON, R. Completing the practice turn in strategy research. Organization studies, v. 27, n. 5, p. 613-634, 2006. 